\section{Drs. Allanore and Vacca reply}

\section{To the Editor:}

We thank Dr. Rios Fernández, et al for their encouraging comments on our study, where we identified the prevalence and associated factors of low vitamin $\mathrm{D}$ values in 2 independent cohorts of patients with systemic sclerosis (SSc) coming from France and Italy ${ }^{1}$. The results in their cohort of 48 patients with SSc from Spain emphasize our findings, as these authors report $81 \%$ of vitamin D deficiency and $9.5 \%$ insufficiency. In our studies, vitamin $\mathrm{D}$ insufficiency and deficiency rates were also very high and comparable between our populations: $82 \%$ and $86 \%$ for insufficiency, $32 \%$ and $23 \%$ for deficiency, respectively, in the French and Italian patients with SSc. Of particular interest, Rios Fernández, et al found these high rates despite a majority of their patients receiving conventional vitamin D supplements $(60 \%)$, whereas $30 \%$ and $45 \%$, respectively, of the patients of our series were receiving supplementation. This clearly strengthens our initial findings, strongly suggesting SSc patients should receive a higher dosage of substitution, although the best regimen remains to be determined. The influence of adapted supplementation and correction of deficiency will also be critical to investigate for the accumulating data showing the implication of vitamin D for immune response $e^{2,3}$. Rios Fernández, et al also investigated osteoporosis in their cohort but failed to identify a link between vitamin D levels and bone mass. Nevertheless, the cross-sectional design of their study may have contributed to these findings, as longitudinal data of serial values would be more relevant. Further, the association of osteoporosis remains a matter of debate, with positive $e^{4,5}$ and negative studies ${ }^{6,7}$ in SSc. The overall improvement of outcomes and survival in their SSc study suggests that osteoporosis will need to be carefully investigated in larger cohorts to clarify whether a specific risk exists and in which subgroup of patients having this severe chronic and disabling condition.
YANNICK ALLANORE, MD, PhD, Paris Descartes University, Department of Rheumatology A, Cochin Hospital, APHP, Paris, France; ALESSANDRA VACCA, MD, University of Cagliari, II Chair of Rheumatology, Azienda Ospedaliero-Universitaria, Cagliari, Italy.

\section{REFERENCES}

1. Vacca A, Cormier C, Piras M, Mathieu A, Kahan A, Allanore Y. Vitamin D deficiency and insufficiency in 2 independent cohorts of patients with systemic sclerosis. J Rheumatol 2009;36:1924-9.

2. Chen S, Sims GP, Chen XX, Gu YY, Chen S, Lipsky PE. Modulatory effects of 1,25-dihydroxyvitamin D3 on human B cell differentiation. J Immunol 2007;179:1634-47.

3. Colin EM, Asmawidjaja PS, van Hamburg JP, Mus AM, van Driel M, Hazes JM, et al. 1,25-dihydroxyvitamin D(3) modulates Th17 polarization and interleukin-22 expression by memory $\mathrm{T}$ cells from patients with early rheumatoid arthritis. Arthritis Rheum 2009;62:132-42.

4. Souza RB, Borges CT, Takayama L, Aldrighi JM, Pereira RM. Systemic sclerosis and bone loss: the role of the disease and body composition. Scand J Rheumatol 2006;35:384-7.

5. Yuen SY, Rochwerg B, Ouimet J, Pope JE. Patients with scleroderma may have increased risk of osteoporosis. A comparison to rheumatoid arthritis and noninflammatory musculoskeletal conditions. J Rheumatol 2008;35:1073-8.

6. Simic Pasalic KA, Pilipovic N, Damjanov N, Gavrilov N, Petric J. Bone mineral density parameters in a group of female patients with systemic sclerosis [abstract]. Ann Rheum Dis 2009;68 Suppl3:465.

7. Loucks J, Pope JE. Osteoporosis in scleroderma. Semin Arthritis Rheum 2005;34:678-82.

J Rheumatol 2010;37:6; doi:10.3899/jrheum.100033 